03

\title{
Взаимодействие газовой струи с неподвижной и вращающейся преградой из высокопроницаемого пористого материала
}

\author{
(C) В.К. Баев, А.Н. Бажайкин ฯ \\ Институт теоретической и прикладной механики им. С.А. Христиановича СО РАН, \\ 630090 Новосибирск, Россия \\ I e-mail: bazhan@itam.nsc.ru
}

(Поступило в Редакцию 15 декабря 2017 г.)

Экспериментально исследовано взаимодействие осесимметричной струи углекислого газа с неподвижной и вращающейся проницаемой для газов преградой. Описаны картины течений и пространственные распределения концентраций $\mathrm{CO}_{2}$ в зависимости от условий экспериментов. Рассмотрена возможность использования полученных результатов для организации различных физико-химических процессов.

DOI: 10.21883/JTF.2018.11.46624.2598

\section{Введение}

Исследование характеристик течений при взаимодействии струи с преградой необходимо для развития ресурсосберегающих технологий, связанных с энергетикой, теплообменными процессами, нанесением различных покрытий и другими применениями. Относительно небольшие затраты на струйную обдувку преград, значительная интенсификация тепломассообмена и полезные эффекты, связанные с перестройкой и турбулизацией течений вблизи преграды, стимулировали множество исследований. В работе [1] дана схема течений при взаимодействии струи с непроницаемой преградой, состоящая из зоны свободной струи, зоны разворота и течения, стелющегося по преграде. Приведены экспериментальные данные и расчеты параметров течений в этих зонах, а также проанализированы условия отрыва потока от преграды и обратного течения струи. В [2] описаны экспериментальные исследования локальных характеристик турбулентности, касательных напряжений и давлений на преграде в зависимости от условий взаимодействия струи с преградой. В [3] проведено численное моделирование вихревой структуры течения и теплообмена в области взаимодействия с преградой и разворота потока.

К настоящему времени разработаны технологии получения новых проницаемых пористых материалов с высокими значениями пористости, удельной поверхности, проницаемости, теплообменных характеристик [4]. Данные свойства существенно расширяют области применения струйных технологий, что требует изучения течений, возникающих при взаимодействии струй с проницаемыми преградами. При натекании струи на проницаемую преграду газ растекается как по поверхности (как на непроницаемой преграде), так и внутри преграды, и часть газа проходит через преграду. Структура таких сложных течений остается малоизученной. В [5] описаны результаты экспериментов и численных расчетов взаимодействия сверхзвуковой воздушной струи и проницаемой преграды, на основании которых представ- лены схемы течений. Согласно схемам, в приосевой зоне перед преградой образуется отрывная зона, имеющая форму вихря, которая огибается основным потоком с формированием зоны разворота на $90^{\circ}$, после которой поток растекается по преграде. Другая часть потока растекается внутри преграды с последующим выходом либо на лицевую ее сторону в растекающийся по ней поток, либо выходит на обратную сторону преграды, образуя течение за преградой. Особенности взаимодействия дозвуковой струи $\mathrm{CO}_{2}$ с высокопроницаемой пористой преградой из никеля (пористость 95\%) кратко изложены в [6], где дана схема течений по поверхности, внутри и позади преграды, а также циркуляционного течения между соплом и преградой. Представляет практический интерес взаимодействие струи с вращающейся проницаемой преградой - диском, обладающим способностью всасывать торцевыми поверхностями газообразные среды, которые внутри диска перемещаются в радиальном направлении и выбрасываются через цилиндрическую поверхность диска [7], т.е. диск может использоваться в качестве элемента вентилятора. Если одновременно подавать к вращающемуся диску среды, имеющие различные свойства, внутри диска могут осуществляться такие процессы, как смешение, теплообмен, массообмен и химические реакции, т.е. проницаемый диск может быть использован в качестве реактора и вентилятора, перемещающего продукты реакций для дальнейшего применения.

В настоящей работе представлены результаты экспериментальных исследований распространения струи углекислого газа $\left(\mathrm{CO}_{2}\right)$ в воздухе и взаимодействия еe с неподвижной и вращающейся преградой (диском) из высокопроницаемого ячеисто-пористого материала (ВПЯМ).

\section{Условия и методика проведения экспериментов}

Схема экспериментов представлена на рис. 1, $a$. Струя впрыскивалась из цилиндрического сопла 1 диамет- 


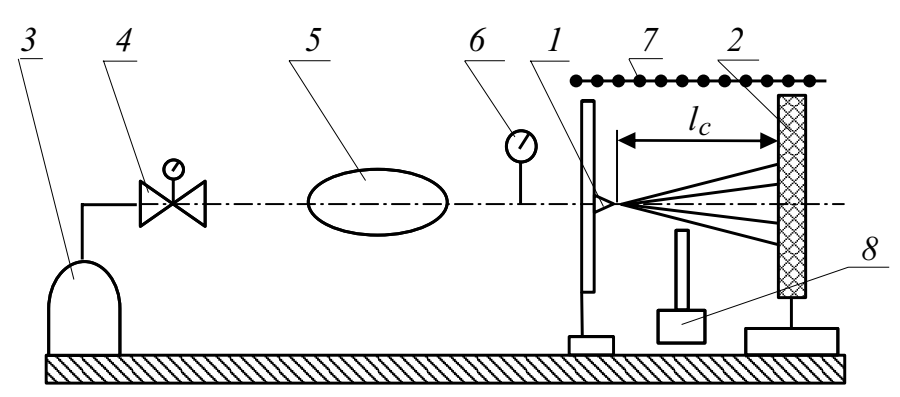

$b$

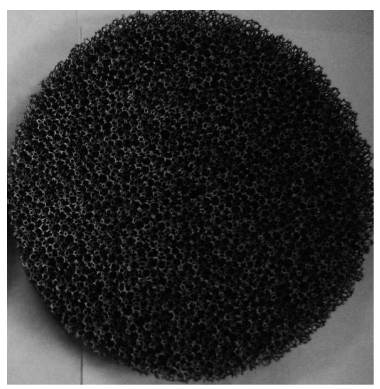

Рис. 1. $a-$ схема постановки экспериментов. $b-$ изображение высокопроницаемой преграды - диска из никелевого ВПЯМ.

ром $0.5 \mathrm{~mm}$ под давлением $0.1-1 \mathrm{~atm}$ на преграду 2 на расстоянии $l_{c}=50-100 \mathrm{~mm}$. Углекислый газ подавался на сопло из баллона 3 через редуктор 4 , счетчик расхода газа (ГСБ-4) 5 с контролем давления впрыска образцовым манометром 6.

В качестве преграды использовался диск из никелевого ВПЯМ, показанный на рис. $1, b$, толщиной $20 \mathrm{~mm}$, диаметром $150 \mathrm{~mm}$, имеющий пористость $95 \%$, размер пор-ячеек 2-4 mm и проницаемость $3 \cdot 10^{-8} \mathrm{~m}^{2}$ [4].

Диагностика процесса включала теневую видеосьемку, визуализацию течений с помощью дыма и газовый анализ среды с помощью капиллярной трубки 8 , соединенной с газоанализатором „Тест ${ }^{\text {“ }} 9$.

Видеосъемка процесса проводилась через теневой прибор ИАБ-451, установленный перпендикулярно оси струи так, чтобы в поле зрения прибора $(240 \mathrm{~mm})$ попадало сопло, диск и пространство за диском. Четкость изображения струи и течений достигалась за счет разницы плотностей впрыскиваемого $\mathrm{CO}_{2}$ и окружающего воздуха при положении ножа Фуко, параллельном оптической щели прибора. При этом кромка ножа регулировалась совпадающей с осью струи так, что половина изображения (относительно оси струи) получалась светлой, а другая половина - темной. Съемка производилась со скоростью 24 кадра в секунду.

Визуализация течений с помощью дыма осуществлялась с помощью нихромовой проволоки 7 , смоченной машинным маслом и установленной над соплом, струей и преградой. При нагреве проволоки током масло собиралось на ней в капли, которые испарялись в виде струек дыма, реагирующих на перепады давлений, создаваемые течениями.

Газовый анализ среды производился при отборе газов капиллярной трубкой 8 с наружным и внутренним диаметрами 1.0 и $0.6 \mathrm{~mm}$, соединенной с газоанализатором 9 марки „Тест“. При измерениях в трубку поступала смесь газов, образовавшаяся непосредственно у среза трубки, независимо от соотношения диаметров сопла и трубки. Газоанализатор позволял определять объемные концентрации $\mathrm{CO}_{2}$ с временным интервалом $5 \mathrm{~s}$ и погрешностью $5 \%$. Отбор проб смеси $\mathrm{CO}_{2}$ с воздухом производился в сечениях, перпендикулярных оси струи на разных расстояниях от сопла, в том числе на поверхностях диска.

\section{Взаимодействие струи $\mathrm{CO}_{2}$ с неподвижной проницаемой преградой (диском)}

Свободная осесимметричная струя $\mathrm{CO}_{2}$, распространяющаяся в неподвижной воздушной среде, перед взаимодействием с преградой пространственно неоднородна по скоростям и концентрациям газа струи. В каждом сечении струи скорости и концентрации $\mathrm{CO}_{2}$ монотонно убывают в радиальном направлении от максимума на оси струи до нуля на периферии. Кроме того, эти характеристики убывают обратно пропорционально длине струи при ее распространении до преграды [1]. Поэтому параметры струи при контакте с преградой определяются скоростью впрыска $U_{0}$, расстоянием от сопла до преграды $l_{c}$ и локальными характеристиками струи.

На рис. 2 представлены теневые изображения натекания струи $\mathrm{CO}_{2}$ на преграду из никелевого ВПЯМ на расстоянии $l_{c}=50 \mathrm{~mm}$ при разных скоростях впрыска $U_{0}=124,175$ и $248 \mathrm{~m} / \mathrm{s}$. При относительно малых скоростях (рис.2,a) видно четкое изображение струи до преграды, перед которой образуется течение от центра к периферии. На некотором расстоянии от оси струи течение отрывается от поверхности преграды и распространяется за пределы преграды. На рис. 2, $a$ также видно, что часть струи проходит через преграду и образует за ней поток, параллельный оси струи. При увеличении скорости струи (рис. $2, b$ ) перед преградой наблюдается неоднородная картина, на фоне которой просматриваются образования в виде колец вокруг струи, изображение которой частично экранируется течениями в пространстве между соплом и преградой. Анализ видеофильма процесса показал, что от преграды постоянно отходят волны возвратных течений (в сторону сопла), в совокупности образующих кольцевой вихрь тороидальной формы с центром в приосевой зоне струи. Течение за преградой, наоборот, спокойное, однородное, „просеянное“ через поры и ячейки, и по форме представляет конус, переходящий в цилиндр. При 


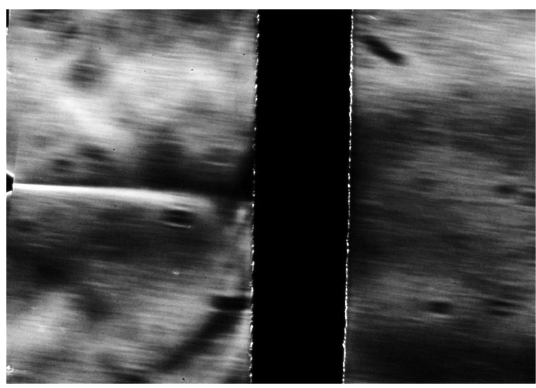

$b$

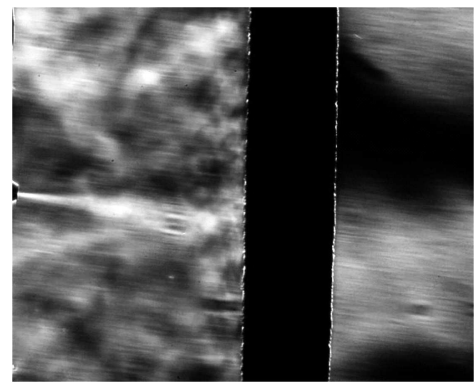

$c$

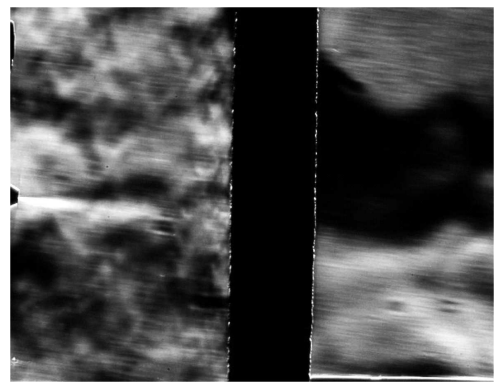

Pис. 2. Теневые изображения взаимодействия струи $\mathrm{CO}_{2}$ с преградой $U_{0}, \mathrm{~m} / \mathrm{s}: a-124, b-175, c-248$.

$a$

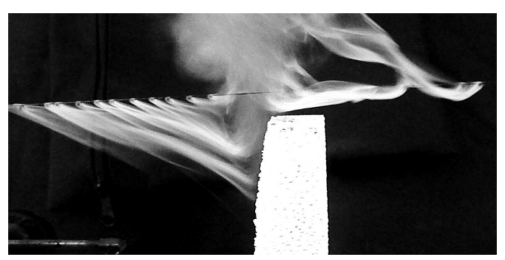

$b$

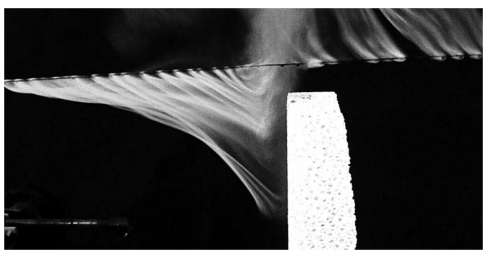

$c$

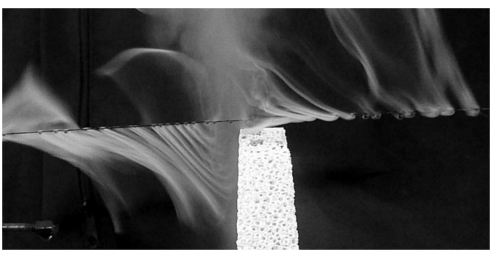

Рис. 3. Визуализация течений с помощью дыма при $U_{0}=240 \mathrm{~m} / \mathrm{s} . a-l_{c}=50, b-l_{c}=60, c-l_{c}=75 \mathrm{~mm}$.

еще больших скоростях впрыска возвратные течения интенсифицируются и могут состоять из нескольких кольцевых вихрей, „вложенных“ друг в друга. Поток за преградой также интенсифицируется и становится менее однородным (рис. 2,c). Измерения изображений показали, что диаметр потока за преградой на 10-20\% меньше диаметра растекающегося по лицевой поверхности преграды потока.

Таким образом, с увеличением скорости струи картина течений перед преградой существенно меняется от растекания по поверхности и отрыва от нее до образования вокруг струи течения, которое циркулирует от преграды в сторону сопла, затем после разворота - в обратном направлении попутно движению струи.

Визуализация течений с помощью дыма производилась при тех же условиях, что и теневая съемка. На рис. 3 показаны изображения, полученные при впрыске $\mathrm{CO}_{2}$ из сопла диаметром $0.5 \mathrm{~mm}$ со скоростью $240 \mathrm{~m} / \mathrm{s}$ на разных расстояниях $l_{c}=50,60$ и $75 \mathrm{~mm}$ соответственно (сопло расположено слева внизу). Струйки дыма между соплом и преградой визуализируют ламинарные линии тока эжектируемого струей $\mathrm{CO}_{2}$ окружающего воздуха и направлены к оси струи. При относительно малых расстояниях $l_{c}=50 \mathrm{~mm}$ (рис. $3, a$ ) струйки не доходят до оси и резко обрываются при взаимодействии с пространственным течением, которым, вероятно, является кольцевой вихрь. Совокупность точек обрыва струек обнаруживает внешние контуры вихря овальной формы. За 5-10 mm до преграды траектории струек резко разворачиваются радиально от оси струи и сливаются в общий поток, стелющийся по преграде, за пределами которой поток расширяется и ,притягивает“ струйки дыма, образовавшиеся позади преграды. При $l_{c}=60 \mathrm{~mm}$ (рис. $3, b)$ струйки обрываются при взаимодействии с вихрем большего диаметра и также разворачиваются перед преградой в общий поток. Дальнейшее увеличение $l_{c}$ (рис. $\left.3, c\right)$ качественно меняет картину: струйки дыма почти достигают оси струи и кольцевой вихрь не образуется. Таким образом, увеличение расстояния между соплом и преградой меняет картину течений аналогично рассмотренному выше уменьшению скорости струи $\mathrm{CO}_{2}$, поскольку скорость контакта струи с преградой обратно пропорциональна $l_{c}$.

Распространение струи $\mathrm{CO}_{2}$, образование течений впереди, внутри и позади проницаемой преграды сопровождаются интенсивным перемешиванием газа с окружающим воздухом. Количественную информацию о составе образующейся смеси $\mathrm{CO}_{2}$ с воздухом позволил получить газовый анализ. На рис. 4 показана трехмерная картина распределения концентрации $\mathrm{CO}_{2}$ $\left(C_{\mathrm{CO}_{2}}\right)$ по длине струи в сечениях радиуса $60 \mathrm{~mm}$, полученная при впрыске с $U_{0}=250 \mathrm{~m} / \mathrm{s}$ на преграду из ВПЯМ, установленную на расстоянии $60 \mathrm{~mm}$ от сопла. У среза сопла (кривая 1) наблюдается резкий пик $\mathrm{CO}_{2}$ на оси струи (в ее ядре), переходящий в плато с концентрациями в 2-2.5\%. В сечении через $20 \mathrm{~mm}$ от сопла (кривая 2) максимум концентрации $\mathrm{CO}_{2}$ на оси значительно уменьшается, а значения $C_{\mathrm{CO}_{2}}$ на плато практически не изменяются. Вблизи преграды (кривая 3) концентрации $\mathrm{CO}_{2}$ в приосевой зоне уменьшается, а в периферийных участках увеличивается до 4-5\%. Полученные результаты показывают, что углекислый газ имеется не только в ядре и в зоне смешения струи, но и в области, значительно превышающий радиус струи в данных сечениях. Поэтому можно предположить наличие $\mathrm{CO}_{2}$ в этой области в результате циркуляции 


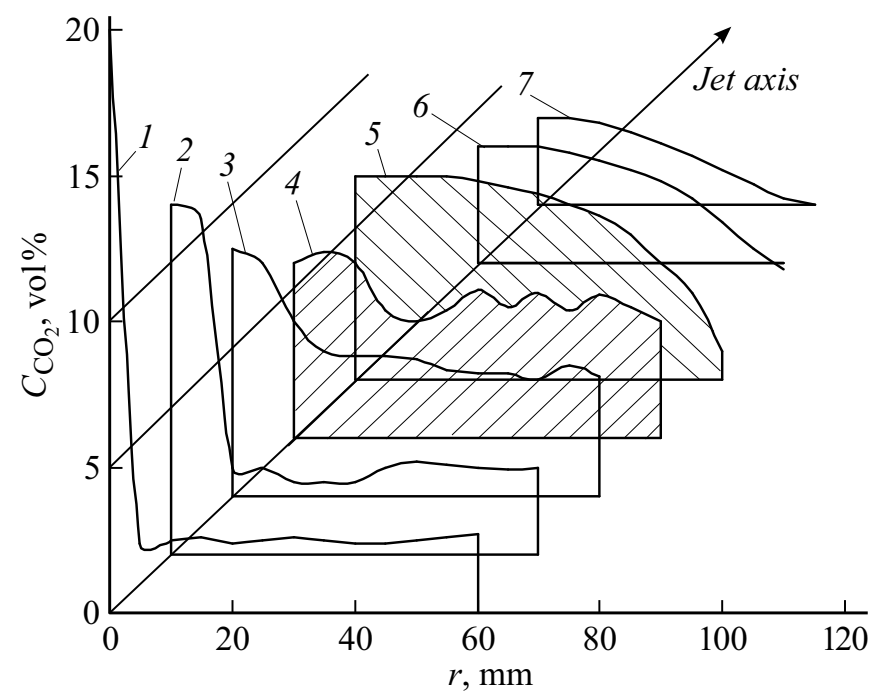

Рис. 4. Распределение концентраций $\mathrm{CO}_{2}$ при натекании струи на преграду.

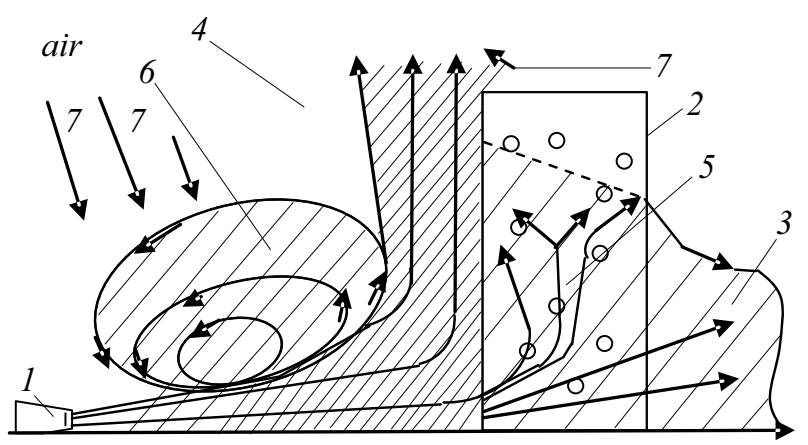

Pис. 5. Схема течений при натекании струи $\mathrm{CO}_{2}$ на преграду: 1 - сопло, 2 - преграда, 3 - течение за преградой, 4 растекание перед преградой, 5 - течение внутри преграды, 6 - циркуляционное течение, 7 - эжекция воздуха.

течения газа между соплом и преградой. На преграде (кривая 4 заштрихована) наблюдается неоднородная картина с четко выраженными минимумами-максимумами и резкими колебаниями $C_{\mathrm{CO}_{2}}$ в точках измерений (на кривых приведены усредненные значения $C_{\mathrm{CO}_{2}}$ ), свидетельствующими о существенной турбулизации течений. На тыльной стороне преграды (кривая 5, заштрихована) все неоднородности сглаживаются, и $C_{\mathrm{CO}_{2}}$ с постоянного максимального значения (5\%) в приосевой зоне струи плавно снижается к периферии. В сечениях, удаленных от преграды (кривые 6,7$) C_{\mathrm{CO}_{2}}$ также плавно снижается от оси к краю сечения, и размеры струи за преградой сокращаются.

Полученные результаты комплексной диагностики, а также литературные данные позволяют представить картину течений, изображенную на рис. 5. При впрыске газовой струи из сопла 1 на проницаемую преграду 2 образуются следующие течения. Течение 3 проходит преграду насквозь с последующим движением в осевом направлении. Течение 4, образующееся при развороте струи перед преградой, распространяется параллельно лицевой поверхности преграды и выходит за ее пределы. Часть струи 5 растекается внутри преграды с последующим выходом либо на ее лицевую поверхность и сливается с растекающимся потоком, либо на заднюю поверхность, соединяясь с течением за преградой. Часть растекающегося перед преградой потока отрывается от последнего и образует возвратное течение, циркулирующее между соплом и преградой и обратно в виде тороидального вихря 6 . При этом в зону циркуляции 6 и в течение 4 эжектируется окружающий воздух 7 с образованием смеси воздуха с газом струи. Представленная схема течений является характерной в исследованном диапазоне изменения условий экспериментов. При относительно малых скоростях контакта струи с преградой струя растекается по преграде и частично проходит ее насквозь; зоны циркуляции 6 при этом не образуется. Поэтому структурой течений и распределением газа струи по течениям можно управлять путем изменения условий натекания струи на преграду.

\section{Взаимодействие струи $\mathrm{CO}_{2}$ с вращающимся высокопроницаемым диском}

Эксперименты проводились при аналогичных условиях и с теми же средствами диагностики, что и с неподвижной преградой - диском. Диск устанавливался на валу электродвигателя (на рис. $1, a$ не показан), обеспечивающий вращение со скоростью $N=0-750 \mathrm{rpm}$. Для того чтобы втулка крепления диска не вносила возмущений в процесс, струя $\mathrm{CO}_{2}$ направлялась на диск с условием, чтобы ее ось пересекала диск на половине его радиуса.

Теневые изображения струи, диска и возникающих в результате их взаимодействия течений, полученные при $U_{0}=250 \mathrm{~m} / \mathrm{s}, l_{c}=60 \mathrm{~mm}$ и различных значениях $N$, показаны на рис. 6. При натекании струи на неподвижный диск (рис. 6,a) образуются течения по поверхности и позади диска, а также циркуляционное течение между соплом (расположено слева) и диском, частично экранирующее струю. При вращении диска (рис. $6, b)$ картина течений меняется: изображение струи просматривается до диска за счет исчезновения циркуляционного течения, течение за диском ограничивается по длине, течение перед диском утончается и появляется течение из цилиндрической поверхности диска. С увеличением $N$ до $500 \mathrm{rpm}$ (рис. 6,c) сохраняется растекание по диску, течение позади диска укорачивается, а течение из цилиндрической поверхности интенсифицируется.

Дополнительной информацией к описываемому процессу является визуализация течений дымом. На рис. 7, $a$ изображено расположение струек дыма при вращении диска без впрыска струи $\mathrm{CO}_{2}$. Траектории струек показывают линии тока окружающего воздуха к лицевой 
$a$

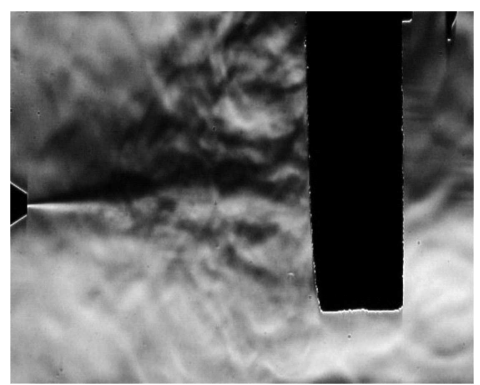

$b$
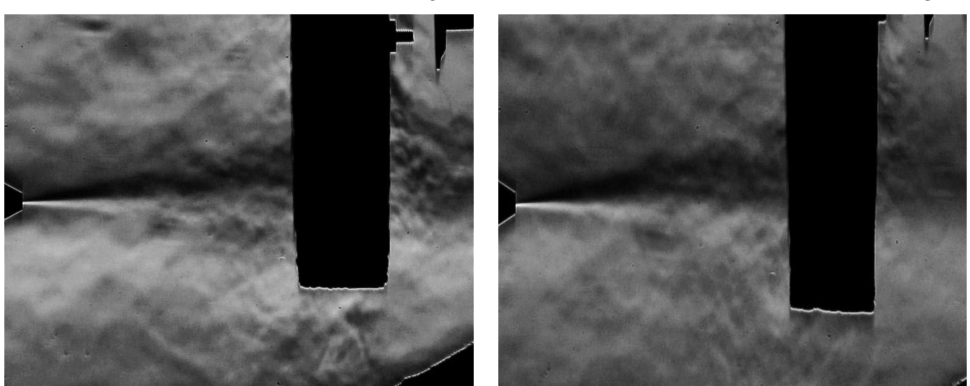

Рис. 6. Теневые изображения взаимодействия струи с вращающимся диском из ВПЯМ. $U_{0}=250 \mathrm{~m} / \mathrm{s}, l_{c}=60 \mathrm{~mm}, a-N=0 \mathrm{rpm}$; $b-N=300 \mathrm{rpm} ; c-N=500 \mathrm{rpm}$.

$a$
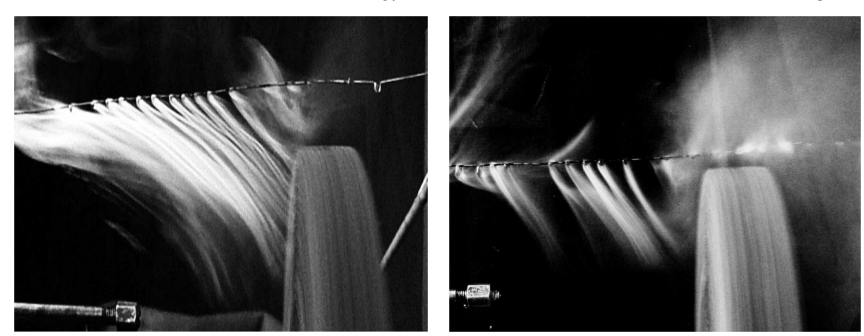

Рис. 7. Визуализация течений дымом при вращении диска. $N=500 \mathrm{rpm}, a-$ без струи $\mathrm{CO}_{2} ; b-$ при впрыске $\mathrm{CO}_{2}$ c $U_{0}=250 \mathrm{~m} / \mathrm{s}$.

поверхности диска, через которую воздух всасывается внутрь диска. При впрыске струи $\mathrm{CO}_{2}$ (рис. 7,b) при тех же значениях $N$ струйки обрываются; совокупность точек обрыва показывают контуры струи, которая растекается по диску и сливается с течением из цилиндрической поверхности. Причем циркуляционное течение, окружающее струю, взаимодействующую с неподвижной преградой (рис. 5), не образуется, поскольку оно уносится потоком всасываемого диском воздуха.

Количественную информацию о составе образующейся смеси $\mathrm{CO}_{2}$ с воздухом позволил получить газовый анализ, для которого отбор проб газа производился в сечениях, перпендикулярных оси струи с шагом $10 \mathrm{~mm}$. На рис. 8 показана трехмерная картина распределения концентраций $\left(C_{\mathrm{CO}_{2}}\right)$ в сечениях струи и на преграде, полученная при $U_{0}=250 \mathrm{~m} / \mathrm{s}, l_{c}=60 \mathrm{~mm}$ и $N=500 \mathrm{rpm}$. У среза сопла (кривая 1) и в последующих сечениях (кривые 2,3) наблюдаются резкие пики концентраций в ядре струи. Ниже по течению струи (кривые 4-6) пиковые значения $C_{\mathrm{CO}_{2}}$ значительно снижаются, и радиус струи увеличивается за счет расширения периферийных участков. На лицевой поверхности диска (кривая 7, заштрихована) концентрации в приосевой части струи относительно выравниваются, снижаясь с 5 до 3.5\%, после чего резко падают и плавно уменьшаются до нуля. На тыльной стороне диска (кривая 8, заштрихована) концентрации $\mathrm{CO}_{2}$ еще более выравниваются, плавно снижаясь с 4 до 2.5\% от центра к периферии. Сравнение представленных данных с результатами, полученными для неподвижного диска (рис. 4), показывает, что перед вращающимся диском поперечные размеры струи существенно сокращаются за счет исчезновения циркуляционного течения, а основная масса $\mathrm{CO}_{2}$ сосредоточена в приосевых участках струи и внутри диска. Внутри вращающегося диска происходит смешение воздуха и углекислого газа и перемещение смеси в радиальном направлении к периферии диска. Для определения состава смеси, выходящей из диска, срез трубки пробоотборника устанавливался в $1-2 \mathrm{~mm}$ от цилиндрической его поверхности и перемещался вдоль ее толщины $(h=20 \mathrm{~mm})$ в осевом направлении. В результате такого сканирования определялся интегральный по сечениям диска состав выходящей смеси, представленный на рис. 9 при различных значениях $N$. Внутри неподвижного диска (кривая 1) газ распределяется относительно равномерно с падением концентрации на тыльной стороне. При вращении и с ростом $N$ концентрации $\mathrm{CO}_{2}$ у лицевой поверхности существенно уменьшаются (кривые 2 4), а максимумы $\mathrm{CO}_{2}$ достигаются в середине диска, после чего наблюдается падение к тыльной стороне

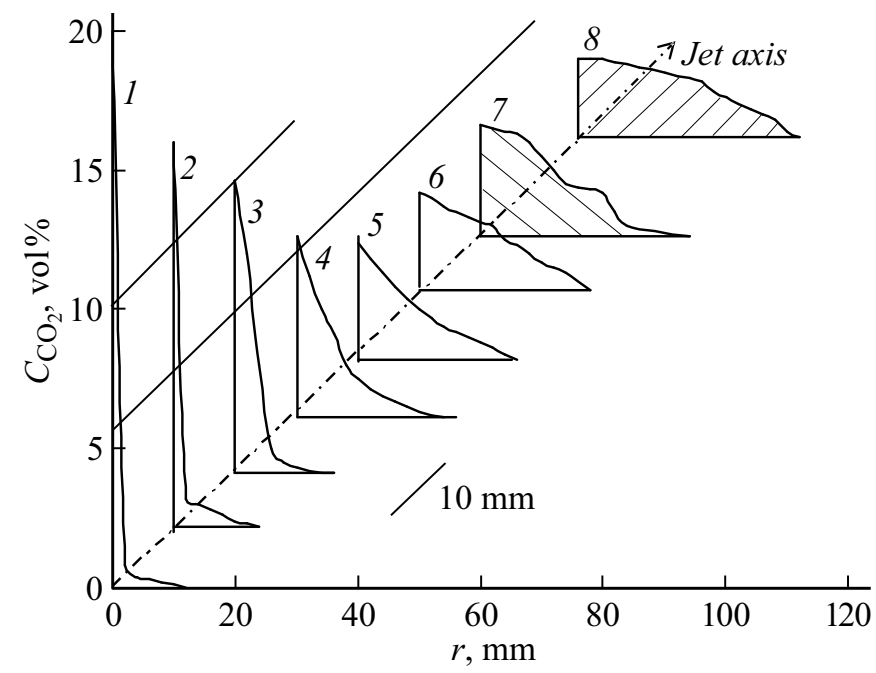

Рис. 8. Распределение концентраций $\mathrm{CO}_{2}$ при натекании струи на вращающийся диск. 


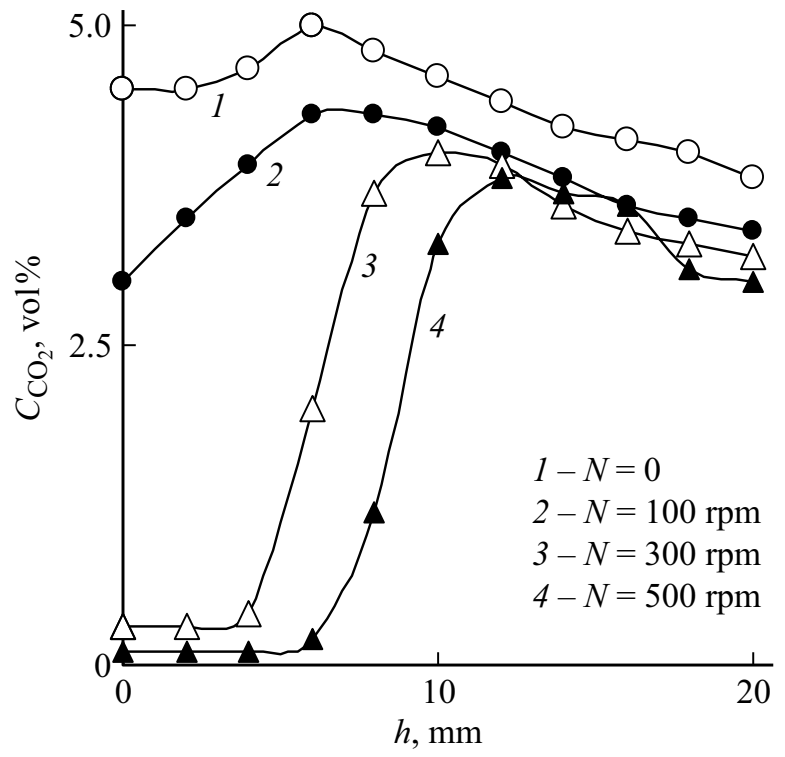

Рис. 9. Распределение концентраций $\mathrm{CO}_{2}$ в смеси, выходящей из диска, по его толщине $(h)$ в зависимости от скорости вращения.

диска. Неоднородность состава смеси, выходящей из диска по его толщине, является результатом влияния различных факторов. Движение струи внутри вращающегося диска определяется действием нескольких сил: инерции - в осевом направлении; гидравлического сопротивления, вызывающего торможение; радиально к периферии диска - под действием центробежных сил; за счет трения о внутренние перегородки ячеек - в тангенциальном направлении. Приосевые участки струи с максимальными скоростями и концентрациями $\mathrm{CO}_{2}$ проходят бо́льшую толщину диска, чем периферийные участки с меньшими скоростями и концентрациями. После торможения все участки струи под действием центробежных сил и трения движутся в радиальном направлении к цилиндрической поверхности диска, где регистрируется концентрационное расслоение по толщине диска, показанное на рис. 9. Отмеченные особенности могут быть использованы в создании устройств для получения и отбора с цилиндрической поверхности диска (при наличии улитки, разделенной на секции) смесей газов заданного состава.

\section{Заключение}

Исследования показали, что при натекании осесимметричной струи на неподвижную высокопроницаемую преграду образуется несколько течений. Часть струи проходит через преграду и за ее пределы в осевом направлении. Часть струи разворачивается перед преградой и разветвляется на течение по ее поверхности и на течение, циркулирующее между соплом и преградой. Часть струи растекается внутри преграды с последующим выходом либо на ее лицевую поверхность, либо на тыльную поверхность, соединяясь с потоком за преградой. При этом струя и течения эжектируют окружающий воздух, который активно перемешивается с газом струи, образуя смесь, состав которой зависит от условий эксперимента. Полученные схема течений и распределение концентраций $\mathrm{CO}_{2}$ использовались при создании устройства для сжигания струи пропан-бутана (по плотности близок к $\mathrm{CO}_{2}$ ) на диске из никелевого ВПЯМ. Испытания показали высокую устойчивость и эффективность процесса [8].

При вращении диска картина течений существенно меняется вследствие образования потоков окружающего воздуха к лицевой и тыльной поверхностям диска, a также влияния центробежных сил. Потоки воздуха увлекают за собой внутрь диска газ струи из циркуляционного течения и из течений впереди и позади диска. Это приводит к тому, что основная часть газа струи оказывается внутри диска и под действием центробежных сил движется, перемешиваясь с воздухом, в радиальном направлении к цилиндрической поверхности диска, откуда выбрасывается наружу. Описанные особенности показывают возможность использования вращающегося проницаемого пористого диска в качестве реактора, в котором при одновременной подаче сред с различными свойствами могут быть реализованы разнообразные физико-химические процессы: смешение, теплообмен, химические реакции, горение, абсорбция. Так, например, совместная подача на вращающийся проницаемый пористый диск загрязненного примесями воздуха и жидкого сорбента позволила провести эффективную сорбционную очистку воздуха от $\mathrm{NH}_{3}, \mathrm{SO}_{2}$ и $\mathrm{CO}_{2}$ [9]. Особенности процесса смешения рассматривались в настоящей работе.

\section{Список литературы}

[1] Абрамович Г.Н. Теория турбулентных струй. М.: Наука, 1984. C. 716.

[2] Алексеенко С.В., Кулеблкин В.В., Маркович Д.М. и др. // ИФЖ. 1996. Т. 69. № 4. С. 615-624.

[3] Волков К.Н. // ПМТФ. 2007. Т. 48. № 1. С. 55-67.

[4] Анциферов В.Н., Храмцов В.Д. // Перспективные материалы. 2000. № 5. С. 56-60.

[5] Запрягаев В.И., Кавун И.Н., Солотчин А.В. // ПМТФ. 2015. T. 56. № 3. C. 73-81.

[6] Баев В.К., Бажсайкин А.Н. // Письма в ЖТФ. 2017. Т. 43. Вып. 5. С. 68-75.

[7] Баев В.К., Фомин В.М., Чусов Д.В. и др. Пат. RU № 2256861. 2005.

[8] Баев В.К., Бажсайкин А.Н. // ФГВ. 2016. Т. 52. № 5. С. $23-$ 32.

[9] Баев В.К., Бажайкин А.Н. // ЖТФ. 2016. Т. 86. № 8. С. 76 82. 